\title{
Assessment of serum vitamin D levels in surgical adolescent idiopathic scoliosis patients
}

\author{
Abdulmonem Alsiddiky ${ }^{1}$, Rheema Alfadhil ${ }^{1}$, Maram Al-aqel', Noura Ababtain', Norah Almajed ${ }^{1}$, Khalid Bakarman',
} Waleed Awwad ${ }^{1}$ and Raheef Alatassi ${ }^{2,3^{*}}$ (D)

\begin{abstract}
Background: The mechanism behind idiopathic scoliosis and its progression is not fully understood. Vitamin D insufficiency is known to play a role in the progression and/or occurrence of a variety of bone diseases. In this study, we aimed to estimate the prevalence of vitamin D insufficiency among patients with adolescent idiopathic scoliosis. Additionally, we aimed to calculate the differences in serum vitamin D levels, Cobb angles, spinal bone mass densities, and serum alkaline phosphatase levels between the sexes in the sample and to assess the possibility of a correlation between any of these factors.
\end{abstract}

Methods: Demographic details, vitamin D levels, Cobb angle, spinal bone mass density, and alkaline phosphatase were collected from the records of 67 patients who were eligible for corrective surgery. These values were compared to normal levels and between the sexes within the study.

Results: Of the 67 patients, 54 (80.6\%) were female. The mean serum vitamin D level was $37.86 \pm 26 \mathrm{nmol} / \mathrm{L}$, and levels below normal were found in $92.5 \%$ of the patients. Statistical analysis showed significant differences $(p=0.002)$ in serum alkaline phosphatase levels between the sexes. No correlation was found between vitamin D levels and the Cobb angles, spinal and bilateral femoral neck bone mass densities, and serum alkaline phosphatase levels.

Conclusions: Most adolescent idiopathic scoliosis patients had insufficient serum vitamin D levels and also suffered from low bone mineral density at an early age.

Keywords: Idiopathic scoliosis, Vitamin D, Cobb angle, BMD, Alkaline phosphatase

\section{Background}

Adolescent idiopathic scoliosis (AIS) is a major public health problem and, despite being relatively rare with a prevalence of $0.47-11.1 \%$ [1], it reduces the quality of life. AIS is a three-dimensional deformity where there is a lateral curvature of the spine. The degree of spinal curvature

\footnotetext{
* Correspondence: raheef332@hotmail.com; ralatassi@sfh.med.sa; raheef.alatassi@mail.mcgill.ca

${ }^{2}$ Department of Orthopedic Surgery, Security Forces Hospital, Riyadh, Saudi Arabia

${ }^{3}$ Department of Orthopedic Surgery, McGill University Health Centre, Jewish General Hospital, Montreal, Canada

Full list of author information is available at the end of the article
}

is evaluated by the Cobb angle. A Cobb angle of more than $10-15^{\circ}$ is considered pathological [2-4]. AIS occurs mostly in adolescents between 10 and 20 years of age and is more prevalent among females [3-7]. In general, scoliosis is considered severe and may require surgical intervention when the Cobb angle exceeds $40^{\circ}$ [8].

The etiology of AIS is still unknown, but multiple theories have been described in the literature [1, 9-11]. Genetic and non-genetic factors have been proposed to cause AIS [12]. Among non-genetic factors is bone mineral density (BMD), as bone quality plays an important role in the derangement of bony mechanical stability. 
Osteoporosis is known to lower the bone strength and the prevalence of AIS with osteoporosis is approximately $20-38 \%[13,14]$.

Vitamin D plays an essential role in maintaining a healthy mineralized skeleton. It helps with calcium absorption, and patients with a deficiency of vitamin D can have difficulties in producing new bone and maintaining their bone strength $[1,12]$.

Recently, several studies have suggested that a decrease in BMD may be responsible for the onset and progression of AIS, and some studies have tried to link vitamin $\mathrm{D}$ to adolescent idiopathic scoliosis $[15,16]$. Despite this progression, there is a lack of studies on the link between vitamin D and AIS, and further studies are necessary to provide pooled evidence for the validation of the association of vitamin D with this clinical entity. Furthermore, exploring the association of vitamin D with AIS might contribute to the understanding of the pathogenesis of spinal deformities in AIS. Vitamin D deficiency is extremely common among the Saudi population despite its sunny weather $[17,18]$. This study aimed to establish the prevalence of vitamin D insufficiency among patients with AIS as well as gender differences in serum vitamin D levels, Cobb angles, BMD, and serum alkaline phosphatase (ALP) level. Further, correlation of vitamin $\mathrm{D}$ with Cobb angles, BMD, and serum ALP levels was evaluated. We hypothesized that subjects with AIS would show vitamin D levels below normal and that these levels would be correlated with Cobb angles, BMD, and serum ALP levels.

\section{Methods}

This retrospective cohort study was conducted in the orthopedic clinic at our institution, from August 2015 to October 2017. Clearance for the ethical approval was obtained from the hospital's ethical committee prior to collecting the data.

Sixty seven consecutive AIS patients, including 13 (19.4\%) males and 54 (80.6\%) females, met the following study criteria: diagnosis of AIS, aged between 10 and 25 years old, Cobb angle of $40^{\circ}$ or more (i.e. requiring corrective surgery), had their serum vitamin $D$ levels measured prior to corrective surgery and had postsurgical follow-up of at least 1 year. Exclusion criteria were having non-idiopathic scoliosis, caused by congenital or neuromuscular conditions, being younger than 10 years or older than 25 years, and having no clinical record of serum vitamin $\mathrm{D}$ levels.

Patient clinical and demographic data, including age, sex, serum vitamin D level, Cobb angle, spinal and bilateral femoral neck BMD, and serum ALP were collected from electronic medical records.

Serum vitamin D [25-hydroxyvitamin D (25(OH)D)] levels were measured by electrochemiluminescence immunoassay (Roche, USA). Cobb angle measurement was obtained by measuring the largest spinal curve, taken from the upper-end vertebra to the lower-end vertebra, on $\mathrm{x}$-ray for all patients included in the study. BMD values were taken from the spine and both femoral necks by using a dual-energy $x$-ray absorptiometry (DEXA) scanner (Lunar, GE medical systems, UK), as it is the most accurate way to measure BMD. Serum ALP was measured using a biochemical auto-analyzer (Siemens Health Diagnostics, USA). According to the manufacturer, normal vitamin D levels are $\geq 75 \mathrm{nmol} / \mathrm{L}$ and insufficient levels are $<75 \mathrm{nmol} / \mathrm{L}$. The normal serum ALP level considered by the manufacturer was $50-180 \mathrm{IU} / \mathrm{L}$.

\section{Statistical analysis}

Data were analyzed using SPSS 21.0 (IBM, Armonk, NY). Descriptive statistics were represented as frequencies and percentages. A one-sample t-test was used to compare the mean vitamin D levels in AIS patients to normal levels. Student's t-test was used to measure the association between categorical variables and outcome variables. A $p$-value of $<0.05$ and $95 \%$ confidence intervals were used to report the statistical significance and precision of estimates. Additionally, a nonparametric correlation test was used to determine the correlation between vitamin $\mathrm{D}$ and the other study variables (Cobb angle, BMD, and ALP).

\section{Results}

The records of 67 patients were included in the study; $54(80.6 \%)$ of them were female, with a mean age of $16 \pm 3.9$ years (range, $10-25$ years). Sixty-two $(92 \%)$ of the patients had low vitamin D levels, with a mean level of $37.86+28 \mathrm{nmol} / \mathrm{L}$. Thirteen (19.4\%) of the patients had low spinal BMD, which was reflected by the low values in their DEXA scans. Moreover, 8 patients (11.9\%) and 7 patients (10.4\%) had low right and left femoral neck BMDs, respectively. The mean spinal BMD was $0.78 \pm 0.26 \mathrm{~g} / \mathrm{cm}^{2}$, and the mean right and left femoral necks BMD was $0.79 \pm 0.13$. The mean Cobb angle was $57.62 \pm 20.5^{\circ}$, with a maximum of $122^{\circ}$. The mean serum ALP value was $170.86 \pm 96.24 \mathrm{IU} / \mathrm{L}$ (Table 1).

The one sample t-test showed that there was a significant decrease in serum vitamin D levels of the patients with AIS compared to the normal serum vitamin D values of healthy individuals. The mean difference was $37.86 \mathrm{nmol} / \mathrm{L}$ (95\% confidence interval [CI]: 31.6; 44.6, $p<0.001)$. The independent t-test showed no significant differences between the male and female groups regarding the vitamin $\mathrm{D}$ levels, Cobb angle, and BMD. The only significant variable was the serum ALP level, which had a mean difference of 120.06 (95\% CI: 60.27; 179.84, $p=0.002$ ) (Table 2). Spearman's correlation testing 
Table 1 Baseline demographics of the scoliosis cohort $(N=67)$

\begin{tabular}{|c|c|}
\hline Variables & Number (\%) \\
\hline Males & $13(19.4 \%)$ \\
\hline Females & $54(80.6 \%)$ \\
\hline Vitamin D Insufficiency & $62(92.5 \%)$ \\
\hline Low spinal BMD & $13(19.4 \%)$ \\
\hline Low Right NOF BMD & $8(11.9 \%)$ \\
\hline Low Left NOF BMD & $7(10.4 \%)$ \\
\hline Elevated Serum ALP & $6(9 \%)$ \\
\hline Age (years) & $16 \pm 3$ \\
\hline Vitamin D (nmol/L) & $37.86 \pm 28$ \\
\hline Mean Cobb Angle $\left({ }^{\circ}\right)$ & $57.62 \pm 20.5$ \\
\hline Spinal BMD $\left(\mathrm{gm} / \mathrm{cm}^{2}\right)$ & $0.78 \pm 0.26$ \\
\hline Left NOF BMD $\left(\mathrm{gm} / \mathrm{cm}^{2}\right)$ & $0.79 \pm 0.13$ \\
\hline Right NOF BMD $\left(\mathrm{gm} / \mathrm{cm}^{2}\right)$ & $0.79 \pm 0.13$ \\
\hline Serum ALP (IU/L) & $170.86 \pm 96.24$ \\
\hline
\end{tabular}

BMD Bone mineral density, ALP Alkaline phosphatase, NOF Neck of femur

revealed no significant correlation between vitamin $D$ values, Cobb angle, BMD, and ALP levels (Table 3).

\section{Discussion}

We studied 67 post-operative AIS patients aged between 10 and 25 years, with the majority of them being females. In a study in Brazil, a similar female preponderance is documented. This suggests that females are more vulnerable to develop AIS $[6,7]$. In the present study, vitamin D insufficiency was more common amongst our sample of AIS patients, which was consistent with previous studies which report that around $91 \%$ of patients show insufficient vitamin D levels [1, 2, 15, 16]. Serum vitamin $\mathrm{D}$ level was compared between male and female patients. We found that female subjects had higher levels than male subjects. However, the difference was not statistically significant. Significant differences were noted when comparing the vitamin $\mathrm{D}$ levels between patients with AIS and healthy subjects from international studies. The findings of the present study are in agreement with previous international studies $[2,15,16]$. A metaanalysis published in 2018 measured vitamin D levels among the Saudi adult population (between the ages of 18 and 80 years) in most regions, and they concluded that vitamin D deficiency was observed in $63.5 \%$ of the population [19]. To the best of our knowledge, no published studies have addressed the presence of vitamin D insufficiency/deficiency in the normal Saudi population of the same age group (10-25 years old).

The level at which the symptoms of Vitamin D deficiency become severe enough to make an impact on the skeleton are not known, neither in the normal population nor in AIS patients. This has led to a belief that a level of $\geq 50 \mathrm{nmol} / \mathrm{L}$ could be considered normal, so that insufficient vitamin D levels would be excluded and only normal vitamin $\mathrm{D}$ or vitamin $\mathrm{D}$ deficient categories would be necessary [19].

The values of Cobb's angle and BMD were not statistically different between males and females in this current study. However, serum ALP was significantly different between male and female patients. Our study showed that serum ALP was found to be elevated in 6 subjects (9\%); this is possibly due to the higher bone turnover rate exhibited by patients with AIS. Similar to the present study, elevated ALP levels have been reported in previous studies [20]. In a study by Shaheen et al., vitamin D-deficient subjects were grouped into mild, moderate, and severe groups according to their serum vitamin D levels. That study found that ALP levels were the highest in the moderate group and the lowest in the severe group [21].

Gozdzialska et al. [15] studied the relationship between ALP levels and sex hormones in pre- and postmenarcheal female subjects. The study concluded that the premenarcheal group had higher ALP values than the postmenarcheal group due to the inhibition of the receptor activator of nuclear factor kappa-B ligand (RANKL) activity, which is known to have an antagonizing effect on osteoclasts within the bone [9-13, 22]. This could explain the significant difference in serum ALP levels found between males and females in this study. This difference could be explained by females generally having higher levels of circulating estrogen, especially during the age of puberty, which could reduce the action of

Table 2 Comparison of the study variables between the male and female groups $(\mathrm{N}=67)$

\begin{tabular}{|c|c|c|c|c|c|c|c|}
\hline \multirow[t]{2}{*}{ Variable } & \multirow[t]{2}{*}{ Male } & \multirow[t]{2}{*}{ Female } & \multirow[t]{2}{*}{ Mean difference } & \multirow[t]{2}{*}{$\mathrm{t}$} & \multirow[t]{2}{*}{$\boldsymbol{p}$-value } & \multicolumn{2}{|c|}{ Confidence interval } \\
\hline & & & & & & Lower & Upper \\
\hline Vitamin D & $33.09 \pm 16.4$ & $39.36 \pm 30.4$ & -6.27 & -0.72 & 0.12 & -23.74 & 11.19 \\
\hline Cobb angle & $64.5 \pm 24.56$ & $56.12 \pm 19.5$ & 8.38 & 1.266 & 0.56 & -4.86 & 21.62 \\
\hline Spinal BMD & $0.81 \pm 0.19$ & $0.77 \pm 0.29$ & 0.04 & 0.38 & 0.49 & -0.16 & 0.24 \\
\hline Left NOF BMD & $0.82 \pm 0.10$ & $0.78 \pm 0.13$ & 0.04 & 0.913 & 0.34 & -0.05 & 0.14 \\
\hline Right NOF BMD & $0.78 \pm 0.12$ & $0.79 \pm 0.13$ & -0.01 & -0.19 & 0.52 & -0.11 & 0.09 \\
\hline ALP & $265.9 \pm 125.53$ & $145.84 \pm 69.64$ & 120.06 & 4.042 & 0.002 & 60.27 & 179.84 \\
\hline
\end{tabular}

BMD Bone mineral density, ALP Alkaline phosphatase, NOF Neck of femur 
Table 3 Correlation between vitamin D and other study variables

\begin{tabular}{lll}
\hline Variables & Correlation coefficient & $\boldsymbol{p}$-value \\
\hline Cobb angle & -0.16 & 0.29 \\
Spinal BMD & 0.11 & 0.47 \\
Right NOF BMD & -0.13 & 0.36 \\
Left NOF BMD & -0.14 & 0.39 \\
ALP & -0.08 & 0.57 \\
\hline
\end{tabular}

$B M D$ Bone mineral density, ALP Alkaline phosphatase, NOF Neck of femur

osteoclasts by inhibiting the action of RANKL, leading to them having a lower bone turnover rate, which translates to lower and more controlled serum ALP levels.

A study conducted in one of the largest spinal units in Saudi Arabia [5], to identify the epidemiological patterns of scoliosis, noted that despite using the standard definition for scoliosis, which is a Cobb angle of $10^{\circ}$ as the minimum lateral spinal angulation [6], most Cobb angles in Saudi patients fell within the surgical range $\left(\geq 40^{\circ}\right)$. The mean Cobb angle at presentation was $58^{\circ}$, which is similar to what was found in our study $\left(57.62 \pm 20.5^{\circ}\right)$. We agree that scoliosis patients in Saudi Arabia requiring surgery are more prevalent, possibly due to the reduced awareness of back deformities within the community and the rather large portion of patients suffering from scoliosis as a complication of poliomyelitis.

The mean Cobb angle in the present study was $57.62 \pm 20.5^{\circ}$, with a maximum angle of $122^{\circ}$. A study done by Lee et al. [8] in Hong Kong studied the extent of Cobb angle severity in relation to BMD status. The subjects in this study were grouped into moderate and severe groups according to their Cobb angles. This indicates that most surgical cases, such as those used in our sample, were considered severe cases in other countries in the far east. They stated that the axial and peripheral BMDs and bone mass content (BMC) in the moderate or severe AIS groups were significantly lower than in controls. They concluded that the higher the Cobb angle, the lower the volumetric and areal BMD and BMC. Despite the difference in geographical location, the results we found were rather similar.

Sadat-Ali et al. [23] compared scoliotic girls with healthy counterparts. BMD was found to be significantly lower in the scoliotic patients, and patients with a Cobb angle of $>30^{\circ}$ had significantly lower bone mass compared to those with a Cobb angle of $<30^{\circ}$. Our study revealed that $13(19.4 \%)$ of our subjects appeared to have low spinal BMD, which is in agreement with the findings of the aforementioned study [22]. Ishida et al. [13] reported that the lumbar spinal BMD of AIS patients was $0.9 \mathrm{~g} / \mathrm{cm}^{2}$, with $51 \%$ being osteopenic and $14 \%$ being osteoporotic. They concluded that there was a significant correlation between the severity of scoliosis and BMD.
The overall decrease in BMD in our study could be due to the increase in bone turnover rate observed in AIS patients. Cheng et al. also found a significant decrease in BMD in AIS subjects [22].

\section{Limitations}

We are aware of several limitations of our study. First of all, the use of controls is designed to minimize the effects of variables other than the independent variable. It would increase the result reliability and would reflect a true image of the normal population. However, in this study, no gender, age, and ethnic-matched controls were ascertained. We understand that having controls may have a significant impact on the results and may change the results completely. Yet, in our study, we compared the means against average values published for the Saudi population. Second, this is a retrospective study, no causal relationship between low vitamin D levels and AIS can be established. Third, ALP levels measured in this study were not bone-specific ALP, which may have affected the results presented from that aspect. Fourth, the small sample size and the fact that this was a single-center study. As a result, we recommend performing prospective multicenter studies with larger series of patients to validate the association of vitamin D in the etiology of AIS. In addition, further studies are required to determine vitamin D levels before and after corrective surgery.

\section{Conclusion}

This study revealed that most AIS patients have insufficient serum vitamin D levels. Furthermore, most AIS patients are also suffering from low BMD at an early age. The study variables were not significantly different between males and females (excluding serum ALP), which indicates that the severity of AIS is not different between sexes. Although low levels of vitamin D were associated with higher Cobb angles, statistical significance could not be reached. Furthermore, no correlation was found between vitamin $\mathrm{D}$ levels and measures of BMD or serum ALP.

\section{Abbreviations}

AIS: Adolescent Idiopathic Scoliosis; BMD: Bone Mineral Density; ALP: Alkaline Phosphatase; RANKL: Receptor Activator of Nuclear Factor Kappa-B Ligand; NOF: Neck of femur

\section{Acknowledgements}

The authors sincerely thank King Saud University, the Vice Deanship of Research Chairs, and the Research Chair of Spinal Deformities for their enthusiastic assistance.

Registration of research studies

This study is registered in Clinical Trials.gov under the following reference number.

NCT03820895 


\section{Authors' contributions}

-AA, MD, Professor of Pediatric Orthopedic and Spine Surgery and Director of Research Chair of Spinal Deformities, reviewed the final version of the manuscript. - RF, orthopedic Surgeon, contributed to the writing of the manuscript and to the data collecting. $-\mathrm{MA}, \mathrm{MD}$, contributed to the writing of the manuscript. -NA, (Noura Ababtain), MD, contributed to the writing of the manuscript and to the data collecting. -NA (Norah Almajed), MD, contributed to the writing of the manuscript. $-K B, M D$, associate professor of pediatric orthopedic surgery, contributed to the writing of the manuscript. -WA, MD, orthopedic spine consultant. Contributed to the writing of the manuscript. -RA, MD, MSc., orthopedic surgeon, performed the literature review and data collection, designed the study, and drafted the manuscript. raheef332@hotmail.com. * All authors read and approved the final manuscript.

\section{Funding}

This research did not receive any specific grant from funding agencies in the public, commercial, or not-for-profit sectors.

\section{Availability of data and materials}

The datasets used and analyzed during the current study are available from the corresponding author on reasonable request.

\section{Ethics approval and consent to participate}

Ethical approval granted by our institutional review board- From IRB committee for CMED 305 Research projects at King Saud UniversityDepartment of Family and Community medicine. Reference number: CMED-305-F6-2015-16.

Written informed consent was obtained from all patients for participation in the study. Moreover, consent was obtained from a parent or guardian on behalf of any participants under the age of 16 .

\section{Consent for publication}

Not applicable.

\section{Competing interests}

The authors have no conflicts of interest to declare.

\section{Author details}

'Research Chair of Spinal Deformities, Department of Orthopedics, King Saud University, College of Medicine, P.O. Box: 3643, Riyadh 11481, Saudi Arabia. 2Department of Orthopedic Surgery, Security Forces Hospital, Riyadh, Saudi Arabia. ${ }^{3}$ Department of Orthopedic Surgery, McGill University Health Centre, Jewish General Hospital, Montreal, Canada.

Received: 21 November 2019 Accepted: 29 April 2020

Published online: 11 May 2020

\section{References}

1. Ng SY, Bettany-Saltikov J, Cheung IYK, Chan KKY. The role of vitamin D in the pathogenesis of adolescent idiopathic scoliosis. Asian Spine J. 2018;12:1127.

2. Batista R, Martins DE, Hayashi LF, Lazaretti-Castro M, Puertas EB, Wajchenberg M. Association between vitamin D serum levels and adolescent idiopathic scoliosis. Scoliosis. 2014;9:045.

3. Janicki JA, Alman B. Scoliosis: review of diagnosis and treatment. Paediatr Child Health. 2007;12:771-6.

4. Konieczny M, Senyurt $H$, Krauspe R. Epidemiology of adolescent idiopathic scoliosis. J Child Orthop. 2012;7:3-9.

5. Al-Arjani A, Al-Sebai M, Al-Khawashki H, Saadeddin M. Epidemiological patterns of scoliosis in a spinal center in Saudi Arabia. Saudi Med J. 2000;21:554-7.

6. Yaman O, Dalbayrak S. Idiopathic scoliosis. Turk Neurosurg. 2014;24:646-57.

7. Brox Jl, Lange JE, Steen H. Comorbidity influenced health-related quality of life of 390 patients with idiopathic scoliosis at long-term follow-up. Eur J Phys Rehabil Med. 2014;50:73-81.

8. Lee W, Cheung C, Tse Y, Guo X, Qin L, Lam T, et al. Association of osteopenia with curve severity in adolescent idiopathic scoliosis: a study of 919 girls. Osteoporos Int. 2005;16:1924-32.

9. Burwell RG, Dangerfield PH, Freeman BJ. Concepts on the pathogenesis of adolescent idiopathic scoliosis. Bone growth and mass, vertebral column, spinal cord, brain, skull, extra-spinal left-right skeletal length asymmetries, disproportions and molecular pathogenesis. Stud Health Technol Inform. 2008;135:3-52.

10. Wang WJ, Yeung HY, Chu WCW, Tang NLS, Lee KM, Qiu Y, et al. Top theories for the etiopathogenesis of adolescent idiopathic scoliosis. J Pediatr Orthop. 2011;31:S14-27.

11. Killian JT, Mayberry S, Wilkinson L. Current concepts in adolescent idiopathic scoliosis. Pediatr Ann. 1999;28:755-61.

12. Owak R, Szota J, Mazurek U. Vitamin D receptor gene (VDR) transcripts in bone, cartilage, muscles and blood and microarray analysis of vitamin $D$ responsive genes expression in paravertebral muscles of juvenile and adolescent idiopathic scoliosis patients. BMC Musculoskelet Disord. 2012;13:259.

13. Ishida K, Aota Y, Mitsugi N, Kono M, Higashi T, Kawai T, et al. Relationship between bone density and bone metabolism in adolescent idiopathic scoliosis. Scoliosis. 2015;10:9.

14. Cook SD, Harding AF, Morgan EL, Nicholson RJ, Thomas KA, Whitecloud TS, Ratner ES. Trabecular bone mineral density in idiopathic scoliosis. J Pediatr Orthop. 1987;7:168-74

15. Gozdzialska A, Jaskiewicz J, Knapik-Czajka M, Drag J, Gawlik M, Ciesla M, et al. Association of calcium and phosphate balance, vitamin D, PTH, and calcitonin in patients with adolescent idiopathic scoliosis. Spine. 2016;41:693-7.

16. Balioglu MB, Aydin C, Kargin D, Albayrak A, Atici Y, Tas SK, et al. Vitamin-D measurement in patients with adolescent idiopathic scoliosis. J Pediatr Orthop B. 2017;26:48-52

17. Al-Othman A, Al-Musharaf S, Al-Daghri N, Krishnaswamy S, Yusuf D, Alkharfy $K$, et al. Effect of physical activity and sun exposure on vitamin D status of Saudi children and adolescents. BMC Pediatr. 2012;12:92.

18. Holick MF, Binkley NC, Bischoff-Ferrari HA, Gordon CM, Hanley DA, Heaney RP, et al. Evaluation, treatment, and prevention of vitamin D deficiency: an Endocrine Society clinical practice guideline. J Clin Endocrinol Metab. 2011; 96:1911-30.

19. Al-Alyani H, Al-Turki HA, Al-Essa ON, Alani FM, Sadat-Ali M. Vitamin D deficiency in Saudi Arabians: a reality or simply hype: a meta-analysis (2008-2015). J Family Community Med. 2018;25(1):1

20. Peacey SR. Routine biochemistry in suspected vitamin D deficiency. J R Soc Med. 2004;97:322-5.

21. Shaheen S, Noor SS, Barakzai Q. Serum alkaline phosphatase screening for vitamin D deficiency states. J Coll Physicians Surg Pak. 2012;22:424-7.

22. Chung CSK, Lee WTK, Tse YK, Lee KN, Guo X, Qin L, et al. Generalized osteopenia in adolescent idiopathic scoliosis - association with abnormal pubertal growth, bone turn over, and calcium intake? Spine. 2006;31:330-8.

23. Sadat-Ali M, Al-Othman A, Bubshait D, Al-Dakheel D. Does scoliosis causes low bone mass? A comparative study between siblings. Eur Spine J. 2008; 17:944-7.

\section{Publisher's Note}

Springer Nature remains neutral with regard to jurisdictional claims in published maps and institutional affiliations.

Ready to submit your research? Choose BMC and benefit from:

- fast, convenient online submission

- thorough peer review by experienced researchers in your field

- rapid publication on acceptance

- support for research data, including large and complex data types

- gold Open Access which fosters wider collaboration and increased citations

- maximum visibility for your research: over $100 \mathrm{M}$ website views per year

At $\mathrm{BMC}$, research is always in progress.

Learn more biomedcentral.com/submission 